\title{
Downhole device design and results of its utilization under acid-implosion action
}

\author{
Grezina Olga Anatolyevna \\ Ufa State Petroleum Technological University, \\ Branch of the University in the City of Oktyabrsky, Russian Federation \\ E-mail: vsh@of.ugntu.ru
}

\begin{abstract}
Complication of producing conditions demands utilization of new technologies. Field test results of acid-implosion action in industrial introduction in order to enhance wells productivity are summarized Design parameters of an implosion device and processing technology provided effective influence in the wells with low permeability carbonate basing filled with highly-viscous oil. The down-hole device based on the bottomhole pump creates an implosion effect, which creates new and enlarges existing holes in the well-bottom zone and their clearage. Simple and reliable device treats the bottom-hole and lifts the fluid to the surface. The technology is cyclic and combines implosion effect with chemical treatment by hydrochloric solution. This technology has been tasted in different combinations of technological operations and different parameters. The results of acid-implosion action are studied by multiple regression method. Character and influence of geologictechnological parameters on technological efficiency will help to choose the wells and their design parameters. Regression equations are used for prognosis evaluation of the effect.
\end{abstract}

Key words-acid-implosive action; well-bottom zone; implosion device; effectivity; multiple regression.

\section{INTRODUCTION}

Utilization of low productive oil deposits is actual nowadays. It is solved by filtration resistance factor in the bottom-hole formation zone (of the well) (BHF). Hydrochloric solutions are widely used for chemical treatment to enhance well productivity in complex technologies [1-5]. For example, it combines with a simple, technological implosion method, which provides cracks creation in the bottom hole [6].

There is a practical experience of acid-implosive action (AIA) [7] in vertical wells of a certain production facility with carbon-bearing reservoir type.

Best practices can include studying conditions and results of down-hole device utilization [8], and determining character and degree of geology-technological conditions influencing on static methods. Potential estimation and effective application of the technology will provide its utilization at suitable facilities.

\section{METHODS AND MATERIALS}

Acid-implosive action was full-filled at the well, which was unprofitable at first. This facility belongs to Kizelovsk carbonate disposals, lies at $1240 \mathrm{~m}$, it is $21.4 \mathrm{~m}$ thick. Contains chalkstones, mean effective oil-filled thickness is
$5.78 \mathrm{~m}$. Mean porosity is $11 \%$, permeability is $0.012 \mathrm{mkm}^{2}$. Degassed oil density is $885 \mathrm{~kg} / \mathrm{m}^{3}$, in-situ oil viscosity is 15.8 $\mathrm{mPa} \cdot \mathrm{s}$. Gas oil ratio is $24.1 \mathrm{~m}^{3} / \mathrm{t}$. paraffin and asphalt - resin substances are 6.2 and $20.5 \%$ respectively. The facility was developed by water flood.

Implosion effectivity is achieved by gradual depression followed by a hydraulic impact [9]. The construction of the device provide repressive (impact) and depressive action. Impact parameters are amplitude and pressure impulse duration. Shock wave parameters at implosion are determined by: vessel (chamber) length, vessel volume, vessel pressure, pressure at which the vessel is filled. Shock wave pressure increases when the vessel length decreases and its diameter increases. Pulse length increases together with the vessel length. Besides, longer the vessel is greater the pulse length is.

A hole-impact-depressive device used in acid-implosive action has barrels of two bottom pumps, which are of the same diameter 43 or $56 \mathrm{~mm}$, connected by a muft. The muft has a hole in the center of $20-25 \mathrm{~mm}$. The inlet valves are taken away before assembly. The end cap is at the bottom barrel. A nipple connects three plunger pistons.

Twin pump cylinders with a muft, an idle inlet valve are descended on the flow column into the well. The pump holes are at the low meter of the perforation interval. Triple plunge descends into the well on the rods and is fixed in the cylinder in the low position.

When the plunge goes up to the holes, low pressure appears in the muft under the plunge. Open holes create depression impact and the fluid goes from the layer and the well into the implosion vessel and the annular fluid goes downwards. When the vessel is filled downward flow stops with a hydraulic impact. During further plunger's movement upwards from holes, there is a further fluid intake through open holes. When the plunger goes downwards from upper position there is no fluid intake, as in common pumps. The fluid flows into the annular space. Fluid intake happens when the plunge goes downwards from the holes. Theoretical device efficiency is comparable with that one of the common well nozzle pump of the same type and size.

The technological scheme is as follows (well killing fluid is oil): well pre-flush by hydrocarbon solvent - lowering the device case on the string tubing- plunge lowering on the stem and fixing it to the cylinder in low position - half-levering of the stem to retrieve the plunge from the cylinder for pumping 
hydrochloric solvent into the well, squeezing it into the annular space - plunge transmission from upwards with a hoist unit - repeating the cycle with the increased amount of acidic agent.

Works [10-16] describe ways to increase oil mobility in all directions over the layer by hydro percussion shockwave device. The authors think there are two mechanisms to explaining shock waves ability to increase oil recovery. In first case, short waves affecting drip oil, separate it from the pore channels and involve it into the fluid stream. The second mechanism means coalescence of oil film, around rock grains, with oil drops, able to transport.

As impact results depend on object choice, quality of technology and technological device, it is possible to access the degree of influence of many factors by statistical method, for example, method of multiple regressions.

\section{RESULTS AND DISCUSSION}

The well device provides the following:

- implosive effect, combining depressive and repressive impact for deposit reconstruction and formation permeability increase;

- multiplicity of action at one lowering of hole equipment; implosive vessel is emptied from the fluid;

- impact duration increases by vessel length elongation;

- number of depression-repression cycles can be regulated;

- combining of well bottom hole treatment with fluid lifting to the surface;

- satisfactory capacity during pumping-off by plunge speed increase by using two cases (cylinders);

- timely pumping-off reaction products from the bottomhole area and the well-bore;

- operating in the fluid of higher viscosity and complicated structure, with inclusions;

- cylinder body integrity maintenance by locating the holes in a connecting nipple for their further common use;

According to the results of practical application the downhole device is effective and reliable.

Its technological peculiarities were determined as a result of field testing and mass use of acid-implosion action:

- practicability of preclearing of a production stem by hydrocarbon solvent or solvent partial squeezing into the well bottom zone;

- partial cleaning of the well bottom zone from the reaction products and contaminants in the view of filling implosion vessel mostly by well fluid (due to high hydraulic resistance of filtering formation fluids in comparison with the high resistance down hole);

- deficiency of a hydraulic shock to improve filtration characteristics of the well-bottom zone because of shock wave propagation from its origin along the well bore;

- lessening application of hydrochloric solvent;

- enhancing void cleanness well-bottom zone thanks to intensive dynamic mode of treatment;

- determining optimal cycle duration timed by acid response or time required to pump one and a half volume of fluid from the bottom-hole zone (counting 10 liters for plunge double stroke);

- practicability of accomplishment of not less than 150 impacts per cycle;

- practicability of production seasoning absence for hydrochloric solvent reaction, which is proved by chemical analysis of the bottom-hole fluid;

- decreasing emulsion formation in the bottom-hole-zone during contact of chlorohydrin acid reaction products and oil by removal of reaction products after treatment;

- practicability of treatment by the conventional flushing device or swabbing after each acid injection cycle or partial squeezing into the bottom hole zone;

- absence of cement stone destruction thanks to impact short duration.

These deductions are proved by the results of the research fulfilled by multiple regression method used to estimate influence of geological-physical and technological parameters on the oil production change fluid watering of the additional oil extraction as the result of acid implosive influence in 50 vertical and sloping wells.

Mean values of acid-implosive impact efficiency for chosen jobs form: incremental oil rate 1.6 tons per day, incremental oil production 1778 tons, effect duration 1282 day. Relative incremental oil production for 28 $\%$ of wells of the group was less than 600 tons.

The list of independent variables (geologo-technical parameters) $x_{i}$ contains: 1 . Effective oil height in the well $H_{\text {e.o., }}$, $\mathrm{m} ; 2$. Average thickness of oil saturated interstratified bed in the well $H_{\mathrm{ib}}, \mathrm{M} ; \mathbf{3}$. Number of oil saturated interstratified beds in the well $n$, units; 4 . Weighted mean layer factor of porosity in the well according to well $\log$ data (WLD) $t, \%$; 5. Oil saturation factor $K_{\mathrm{s}}, \%$; 6 . Amount of container rocks in the total layer thickness $K_{\mathrm{cr}}$, units; 7. Distance to water-bearing bed $h_{\mathrm{w}}, \mathrm{m} ; \mathbf{8}$. Time from the beginning of the well exploitation till the moment of acid-implosion action (AIA) $t$, day; 9. Well production before the time of AIA $q$ prod max, t/day; 10. Well production at the time of AIA $q_{\text {prodl }}$, t/day; 11. Well stream watering at the moment of $\operatorname{AIA} f_{1}, \% ; 12$. Cumulative oil production at the moment of AIA $Q_{\text {o.cum }}, \mathrm{T} ; 13$. Current layer pressure at the moment of AIA $P_{\text {lay }}^{\text {curr }}, \mathrm{MPa}$; 14. Layer pressure relative decrease during AIA (relation of the current layer pressure to the starting) $P_{\text {lay }}{ }^{\text {cur }} / P_{\text {lay }}{ }^{\text {start }}, \% ; \mathbf{1 5}$. Asphaltenedeposits dissolvent volume (for flow tubing cleaning without overflush) $V_{\text {dis.asp-dep }}^{\text {tub }}, \mathrm{m}^{3} ; 16$. Asphaltene-deposits dissolvent volume (for over flush) $V_{\text {dis.asp-dep }}{ }^{\text {BHZ }}, \mathrm{m}^{3} ; 1$ 17. Chlorhydric acid volume, $V_{\text {acid }}, \mathrm{m}^{3} ; 18$. Chlorhydric acid concentration $K, \%$; 19. Acid placement cycle numbers, $n_{\text {ac., }}$ unit; 20. Total number of plunge double strokes $n_{\text {p.s., }}$ unit; 21. Number of swabbing operations $n_{\text {swabbing }}$, unit; 22. Multiplicity factor AIA $N$, unit.

Independent variables characterize layer geologicalphysical characteristics, technological characteristics of well and layer operation, influence implementation.

As dependent variables (impact efficiency factor) $y_{i}$ are chosen: absolute $y_{1}$ (t/day) and relative $y_{2}(\%)$ initial incremental oil rate absolute $y_{3}(\%)$ and relative $y_{4}(\%)$ water 
production lowering, additional oil extraction $y_{5}=\Delta Q_{o i l}(\mathrm{t})$ and effect durability $y_{6}=T$ (day) [17-19].

The most important parameters of a static model are estimated according to the value of standardized regression coefficients (Beta-coeficient). Estimation results for AIA are given in [20-22].

The following design parameters influence the technological efficiency the most:

- Asphaltene-deposits dissolvent volume (for flow tubing cleaning without or with the overflush);

- Number of swabbing operations.

AIA effectivity increases with lessening the volume of hydrochloric solvent, acid placement cycle numbers, repetition of action.

Increase of plunge double strokes results in lessening of after AIA fluid water cut.

Layer pressure increase, on one hand, contributes to products reaction carrying out from well-bottom zone, on the other hand, relation of the hydraulic impact pressure to ground pressure may decrease.

The connection of these AIA efficiency factors with the chosen factors is very high (for relative lowering of the water cut it is significant). These equations are recommended for quality-quantitative scoring:

$$
\begin{aligned}
& y_{2}=\Delta q_{\text {prod }} / q_{\text {prod } 1}=\left(q_{\text {prod } 2}-q_{\text {prod } 1}\right) / q_{\text {prod } 1}=- \\
& +22,55 H_{\text {e.o. }}-24,58 H_{\text {ib }}-41,19 n-3,224 m+ \\
& +7,895 K_{s}-59,34 K_{c r}+3,086 h_{w}-0,015 t- \\
& -21,01 q_{\text {oil } \max }-107,44 q_{\text {oil } 1}-1,029 f_{1}-0,000 Q_{o} \\
& +15,91 P_{\text {lay }}^{\text {cur }}-0,156 P_{\text {lay }}^{\text {cur }} / P_{\text {lay }}^{\text {star }}+3,713 V_{\text {dis.asp-dep }}^{\text {tub }} . \\
& +46,508 V_{\text {dis.asp-dep }}^{\text {BZP }}-8,453 V_{\text {acid }}-1,969 K+24,0 \\
& -0,049 n_{p s .}+24,19 n_{\text {swab }}+45,29 N \quad(R=0,831)
\end{aligned}
$$

$$
\begin{aligned}
& y_{3}=\Delta f=f_{1}-f_{2}=-3,185+0,8960 H_{e . o .}-1,33 \\
& -1,868 n-0,0990 m+0,2162 K_{s}-6,105 K_{r}+ \\
& +0,1281 h_{6}-0,00016 t-0,8864 q_{o i l \max }-1,889 q_{c} \\
& +0,3957 f_{1}-0,00001 Q_{o / \text { inc }}+0,2416 P_{\text {lay }}^{\text {cur }}+ \\
& +0,00239 P_{\text {lay }}^{\text {cur }} / P_{\text {lay }}^{\text {star }}+0,05704 V_{\text {dis. } \text {-aspdep }}^{\text {BHZ }}+ \\
& +0,4687 V_{\text {dis.asp-dep }}^{\text {BHZ }}-0,8141 V_{\text {acid }}-0,5247 K+ \\
& +2,880 n_{\text {ac. }}+0,00723 n_{p s .}+5,241 n_{\text {swab }}- \\
& -1,048 N(R=0,852),
\end{aligned}
$$

$$
\begin{aligned}
& \mathrm{y}_{5}=\Delta \mathrm{Q}_{\mathrm{o}}=-3510,58-103,5 \mathrm{H}_{\text {o.e. }}-533,3 \mathrm{H}_{\text {lay }} \\
& -652,1 \mathrm{n}+335,3 \mathrm{~m}+18,64 \mathrm{~K}_{\mathrm{s}}+2838,2 \mathrm{~K}_{\mathrm{cr}}+ \\
& +35,27 \mathrm{~h}_{\mathrm{w}}-0,16 \mathrm{t}-307,1 \mathrm{q}_{\text {oilmax }}-608,4 \mathrm{q}_{\text {oill }}- \\
& -51,11 \mathrm{f}_{1}+0,02 \mathrm{Q}_{\text {oil.inc }}+334,1 \mathrm{P}_{\text {lay }}^{\text {curr }}-7,5 \mathrm{P}_{\text {lay }}^{\text {curr }} / \mathrm{P}_{\text {la }}^{\mathrm{s}} \\
& +317,8 \mathrm{~V}_{\text {dis. asp dep }}^{\text {BHz }}+311,4 \mathrm{~V}_{\text {dis. asp.dep. }}^{\text {BHZ }}-107,3 \mathrm{~V}_{\text {acid }}- \\
& +143,7 \mathrm{n}_{\text {ac. }}-0,36 \mathrm{n}_{\text {p.s. }}+32,99 \mathrm{n}_{\text {swab }}+993,13 \mathrm{~N} \\
& (\mathrm{R}=0,724) .
\end{aligned}
$$

\section{CONCLUSION}

Acid-implosive action can be fulfilled effectively with the down-hole device, based on bottom oi -well pump. Repeated implosion effect provides crack formation and expansion in the bottom-hole zone, as well as pores and cracks cleaning from contaminants.

Практические результаты воздействия достигнуты in vertical and slanting production wells low-permeability carbonate basin, saturated with sulphuric, high-paraffin viscous oil.

Practical tests correspond to conclusions, received during estimation of character and influence degree of geologyphysical and technological parameters oil flow and watering cut rate by multiple regression method, incremental oil production. The regressive equations can be used for qualityquantitative assessment of impact predicted results.

It is sensible to determine qualitative criteria for effective technology application.

\section{References}

[1] V.V. Sergeev, N.G. Belenkova, Yu.V. Zeigman, and V.Sh. Mukhametshin, "Physical properties of emulsion systems with $\mathrm{SiO}_{2}$ nanoparticles," (in Russian), Nanotechnologies in Construction, vol. 9, no. 6, 2017, pp. 37-64. DOI: 10.15828/2075-8545-2017-9-6-37-64.

[2] V.V. Mukhametshin, "Efficiency estimation of nanotechnologies applied in constructed wells to accelerate field development," (in Russian), Nanotechnologies in Construction, vol. 10, no. 1, 2018, pp. 113-131. DOI: 10.15828/2075-8545-2018-10-1-113-131.

[3] K.J. Webb, C.J.J. Black, and G. Tjetland, "A Laboratory Study Investigating Methods for Improving Oil Recovery in Carbonates," International Petroleum Technology Conference (Doha, Qatar: International Petroleum Technology Conference), 2005, pp. 1-6. DOI: 10.2523/IPTC-10506-MS.

[4] J.M. Economides, and K.I. Nolte. Reservoir stimulation. West Sussex, England: John Wiley and Sons, 2000.

[5] R.T. Akhmetov, A.V. Andreev, and V.V. Mukhametshin, "Residual oil saturation and the displacement factor prediction methodology based on geophysical studies data to evaluate efficiency of nanotechnologies application," (in Russian), Nanotechnologies in Construction, vol. 9, no. 5, 2017, pp. 116-133. DOI: 10.15828/2075-8545-2017-9-5-116133.

[6] A.A. Popov. Implosion in the processes of oil production. Moscow: Nedra, 1996

[7] E.I. Suleymanov, G.G. Ganiev, A.I. Ivanov, M.Kh. Valeev, and A.A. Sivukhin. Patent no. 2117145 Russian Federation, MPK E 21 B 43/25. Production well bottom hole formation zone treatment technique, patentee and assignee OGPD «Bavlyneft» OJSC «Tatneft». No. 98103573/03. Declared 27.02.98. Published 10.08.98. Bulletin No. 22. $4 \mathrm{p}$. 
[8] G.G. Ganiev, A.I. Ivanov, M.Kh. Valeev, A.A. Sivukhin, and A.V. Dolzhenkov. Utility model patent certificate no. RU8049U1 Russian Federation, MPK E 21 B 43/25 (1995.01). A device for oil production and processing bottomhole zone, patentee and assignee CJSC «Aloil». No. 98104661/20. Declared 25.03.1998. Published 16.10.1998. 7 p.

[9] R.R. Ibatullin, E.D. Podymov, R.R. Kadyrov, and M.Kh. Musabirov, "EOR improvement as one of the TatNIPIneft business priorities," (in Russian), Oil Industry, Vol. 7, 2010, pp. 36-39.

[10] S.V. Bortkevich, V.O. Vuden, and S.A. Kostrov, "Hydro-shock technology to increase oil production and oil recovery," (in Russian), Oil \& Gas Tecnology, Vol. 6, 2005, pp. 5-6.

[11] S. Kostrov, and W. Wooden, "Mechanizm. Field Suitability and Using In Situ Seismik Stimulation," Nonlinear Acoustics - Fundamentals and Applications: 16-th International Symposium on Nonlinear Acoustics ISNA 16 (Moscow, Russia), 2002, pp. 228-236.

[12] V.V. Mukhametshin, and R.R. Kadyrov, "Influence of nanoadditives on mechanical and isolating properties of cement-based compositions," (in Russian), Nanotechnologies in Construction, vol. 9, no. 6, 2017, pp. 1836. DOI: $10.15828 / 2075-8545-2017-9-6-18-36$.

[13] V.Sh. Mukhametshin, Yu.V. Zeigman, and A.V. Andreev, "Rapid assessment of deposit production capacity for determination of nanotechnologies application efficiency and necessity to stimulate their development," (in Russian), Nanotechnologies in Construction, vol. 9, Vol. 3, 2017, pp. 20-34. DOI: 10.15828/2075-8545-2017-9-3-20-34.

[14] V.N. Polyakov, Yu.V. Zeigman, Yu.A. Kotenev, V.V. Mukhametshin, Sh.Kh. Sultanov, and A.P. Chizhov, "System solution for technological problems of well construction completion," (in Russian), Nanotechnologies in Construction, vol. 10, no. 1, 2018, pp. 72-87. DOI: 10.15828/2075-8545-2018-10-1-72-87.

[15] X. Xie, W.W. Weiss, Z.J. Tong, and N.R. Morrow, "Improved Oil Recovery from Carbonate Reservoirs by Chemical Stimulation," SPE
Journal, vol. 10, no. 3, 2005, pp. 1-10. DOI: 10.2118/89424-PA.

[16] B. Lungwitz, C. Fredd, M. Brady, M. Miller, S. Ali, and K. Hughes, "Diversion and Cleanup Studies of Viscoelastic Surfactant-Based SelfDiverting Acid," SPE International Symposium and Exhibition on Formation Damage Control (Lafayette, Louisiana: Society of Petroleum Engineers), 2004, pp. 1-10. DOI: 10.2118/86504-MS.

[17] V.V. Mukhametshin, V.E. Andreev, G.S. Dubinsky, Sh.Kh. Sultanov, and R.T. Akhmetov, "The Usage of Principles of System GeologicalTechnological Forecasting in the Justification of the Recovery Methods," SOCAR Proceedings, Vol. 3, 2016, pp. 46-51. DOI: 10.5510/OGP20160300288.

[18] V.Sh. Mukhametshin, "Dependence of crude-oil recovery on the well spacing density during development of low-producing carbonate deposits," (in Russian), Oil Industry, Vol. 12, 1989, pp. 26-29.

[19] V.V. Mukhametshin, "Eliminating uncertainties in solving bottom hole zone stimulation tasks," Bulletin of the Tomsk Polytechnic University. Geo Assets Engineering, vol. 328, no. 7, 2017, pp. 40-50.

[20] O.A. Grezina, "Efficiency evaluation for nanomaterials applied in well bottom zone treatment after completion of well construction," (in Russian), Nanotechnologies in Construction, vol. 9, no. 6, 2017, pp. 6586. DOI: $10.15828 / 2075-8545-2017-9-6-65-86$.

[21] R.G. Khannanov, R.M. Shakirov, A.A. Sivukhin, and O.A. Grezina, "Bottomhole formation zone complex treatment technology as a priority development direction for complex structure carbonate reservoirs stimulation techniques in OGPD «Bavlyneft»," (In Russian), Georesursy, Vol. 3, 2006, pp. 15-17.

[22] E.D. Podymov, S.I. Ibatullina, T.P. Samoilova, and G.N. Farkhutdinov, "Efficiency of application of technologies of oil recovery increase at Tatneft OAO oil deposits development," (in Russian), Oil Industry, no. 7, 2007, pp. 70-74 